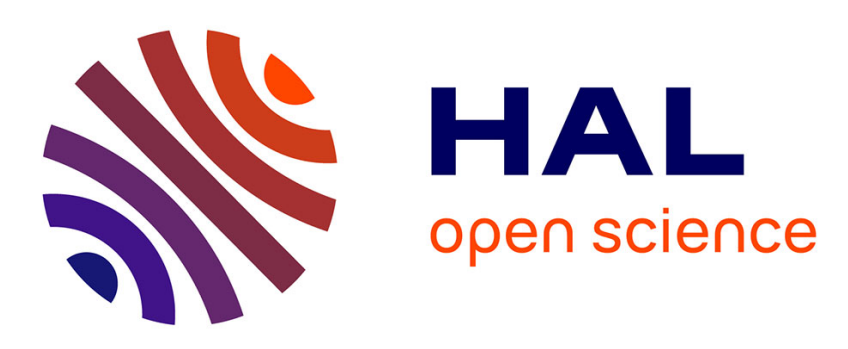

\title{
Immunohistochemical detection of arginine methylated proteins (MeRP) in archival tissues
}

\author{
Marzia Vezzalini, John M Aletta, Stefania Beghelli, Eisabetta Moratti, Marco \\ Della Peruta, Andrea Mafficini, Wilfrido D. Mojica, Aldo Mombello, Aldo \\ Scarpa, Claudio Sorio
}

\section{To cite this version:}

Marzia Vezzalini, John M Aletta, Stefania Beghelli, Eisabetta Moratti, Marco Della Peruta, et al.. Immunohistochemical detection of arginine methylated proteins (MeRP) in archival tissues. Histopathology, 2010, 57 (5), pp.725. 10.1111/j.1365-2559.2010.03684.x . hal-00593449

\section{HAL Id: hal-00593449 \\ https://hal.science/hal-00593449}

Submitted on 16 May 2011

HAL is a multi-disciplinary open access archive for the deposit and dissemination of scientific research documents, whether they are published or not. The documents may come from teaching and research institutions in France or abroad, or from public or private research centers.
L'archive ouverte pluridisciplinaire $\mathbf{H A L}$, est destinée au dépôt et à la diffusion de documents scientifiques de niveau recherche, publiés ou non, émanant des établissements d'enseignement et de recherche français ou étrangers, des laboratoires publics ou privés. 


\section{Histopathology}

\section{Immunohistochemical detection of arginine methylated proteins (MeRP) in archival tissues}

\begin{tabular}{|r|l|}
\hline Journal: & Histopathology \\
\hline Manuscript ID: & HISTOP-12-09-0672 \\
\hline Manuscript Type: & Original Article \\
\hline Author: & 03-Dec-2009 \\
\hline Complete List of Authors: & $\begin{array}{l}\text { Vezzalini, Marzia; University of Verona, Department of Pathology } \\
\text { Aletta, John; CH3 BioSystems LLC, New York State Center of } \\
\text { Excellence in Bioinformatics \& Life Sciences } \\
\text { Beghelli, Stefania; University of Verona, Department of Pathology } \\
\text { Moratti, Eisabetta; University of Verona, Department of Pathology } \\
\text { Della Peruta, MArco; University of Verona, Department of Pathology } \\
\text { Mafficini, Andrea; University of Verona, Department of Pathology } \\
\text { Mojica, Wilfrido; University at Buffalo, Department of Pathology } \\
\text { Mombello, Aldo; University of Verona, Department of Pathology } \\
\text { Scarpa, Aldo; University of Verona, Department of Pathology } \\
\text { Sorio, Claudio; University of Verona, Department of Pathology }\end{array}$ \\
\hline Keywords: & $\begin{array}{l}\text { Methylarginine, cancer, PRMT, immunohistochemistry, normal } \\
\text { tissue }\end{array}$ \\
\hline & \\
\hline
\end{tabular}

\section{S) ScholaroNE \\ Manuscript Central}


Immunohistochemical detection of arginine methylated proteins (MeRP) in archival tissues

Marzia Vezzalini ${ }^{1}$, John M. Aletta ${ }^{2}$, Stefania Beghelli ${ }^{3}$, Elisabetta Moratti ${ }^{1}$, Marco Della Peruta $^{1}$, Andrea Mafficini ${ }^{3}$, Wilfrido D. Mojica ${ }^{4}$, Aldo Mombello ${ }^{1}$, Aldo Scarpa ${ }^{1,3}$ and Claudio Sorio ${ }^{1,3^{*}}$

${ }^{1}$ Department of Pathology, University di Verona, Verona, Italy

${ }^{2} \mathrm{CH} 3$ BioSystems LLC, New York State Center of Excellence in Bioinformatics \& Life Sciences, Buffalo, New York 14203, USA

${ }^{3}$ ARC-NET Center for Applied Research on Cancer, Hospital Concern and University School of Medicine, Verona, Italy

${ }^{4}$ Department of Pathology, University at Buffalo, New York 14203, USA

Running title: In situ analysis of Methylarginine

Keywords: Methylarginine, PRMT, immunohistochemistry, cancer, normal tissue

*Corresponding author for page proofs, correspondence and requests for reprints

Dr. Claudio Sorio, Department of Pathology, University of Verona, Strada Le Grazie 8, 37134 Verona, Italy Tel: +39-045-8027688, Fax: +39-045-8027127, e-mail: claudio.sorio@univr.it 
Support: This study was supported by Associazione Italiana Ricerca sul Cancro (AIRC) Veneto Region Grant, Milan, Italy; Fondazione Cariparo, Padova, Italy; Ricerca Sanitaria Finalizzata Regione Veneto; Ministero della Salute - project RF-EMR-2006-361866;

European Community FP6 "MolDiagPaca”.

Disclosure: JMA is a co-founder and the Principal Scientist of CH3 BioSystems LLC. He is named as inventor on USPTO 6699673, "Protein Methylarginine-Specific Antibodies" and on the provisional patent application "Methylarginine Detection in Cells and Tissues". 


\begin{abstract}
(195 words)
Aims: i) To determine if methylarginine-specific antibodies can be employed for standard immunohistochemical analysis of paraffin-embedded tissues, ii) analyze methylarginine expression in normal and neoplastic tissues, and iii) correlate methylarginine expression with that of PRMT1, the predominant cellular arginine methyltransferase.
\end{abstract}

Methods and Results: Immunohistochemical staining of normal and cancer tissues utilizing three commercial polyclonal antibodies: anti-mRG raised against a methylarginine peptide, anti-RG, a control antiserum raised against a corresponding arginine peptide without any methylated residues, and anti-PRMT1.

Nuclear and/or cytoplasmic methylarginine expression was detected in all keratinized and non-keratinized epithelia. A preliminary survey of a series of thyroid, pancreatic, colon and gastric cancers identified a different pattern of methylarginine expression in comparison with normal tissue. A correlation between methylarginine staining and PRMT1 expression was found in all normal and cancer tissues analyzed.

Conclusion: This study reports for the first time that methylarginine-specific antibodies are capable of recognizing MeRP in paraffin-embedded tissues. Methylarginine proteins are widely expressed and show differences in subcellular localization in various organs and neoplastic conditions. The efficient detection of methylproteins by standard immunohistochemistry demonstrated in this study provides a new tool to investigate the role of MeRP in biological processes including carcinogenesis. 


\section{INTRODUCTION}

Proteins containing methylarginine residues have been implicated in a wide variety of human diseases, but the detection of methylarginine proteins (MeRP) in normal and pathological tissue specimens has not been reported.

The post-translational methylation of arginine has been described for proteins that exert an important role in transcriptional regulation ${ }^{1-3}$. The modification of arginine side chain guanidino groups is quantitatively one of the most extensive post-translational modifications of proteins in mammalian cells $\mathrm{s}^{4,5}$. The protein arginine methyltransferase (PRMT) family of enzymes is responsible for the methyl-transfer reaction using Sadenosyl-L-methionine as the methyl donor. These enzymes catalyze the formation of mono-methylarginine and asymmetric or symmetric di-methylarginine in mammalian cells. Six genes with PRMT catalytic subunits are known to date (PRMT1, 3, 4, 5, 6, and 8) and three other genes encode sequence-related proteins with possible methyltransferase activities (PRMT2, 7, and 9) ${ }^{6,7}$. The number of distinct modified proteins is also diverse ${ }^{8}$. Further diversity of the methylation reactions occurring in living cells is added by alternative splicing mechanisms ${ }^{9}$. Individual members of the PRMT family differ in abundance, activity, substrate specificity and intracellular localization indicating non-redundant roles in vivo. The predominant member of the PRMT family, PRMT1, is an essential enzyme responsible for approximately $85 \%$ of all arginine methylation reactions in human and mouse cells ${ }^{10-12}$. PRMT1 generally recognizes arginines within a glycine-arginine-rich (GAR) region, a motif present in many RNA- and DNA-binding proteins. 
Based on the rapid expansion of biomedical research implicating methylarginine proteins in gene expression and other fundamental biological functions, the study of protein arginine methylation holds great promise for extending our understanding of human developmental and pathological processes ${ }^{13,14}$. Antibodies have been developed that specifically recognize a canonical methylarginine peptide sequence and the major arginine methyltransferase in eukaryotic cells, PRMT1 ${ }^{15,}{ }^{16}$; however a method for rapid screening of the process in biological tissues is lacking. Although western blotting is a sensitive and quantitative assay that has been used to assess methylation status, it is not suited for high-throughput analysis.

Here we report that methylarginine proteins may be detected by immunohistochemistry on archival tissues using available commercial antibodies and describe for the first time the distribution of MeRPs in normal tissue. We also provide evidence of altered expression/redistribution of MeRP in neoplastic tissues. 


\section{MATERIALS AND METHODS}

Tissues

Formalin-fixed paraffin-embedded human normal and cancer tissues were retrieved from the archives of the Department of Pathology of the University of Verona.

\section{Antibodies}

The IgG-purified rabbit antibodies used in this work have been described ${ }^{15,16}$. They were polyclonal rabbit anti-mRG, anti-RG (CH3 BioSystems LLC, Buffalo, NY) and antiPRMT1 IgG purified by Protein A Sepharose chromatography ${ }^{17}$ (a generous gift from Dr. Harvey Herschman, UCLA).

\section{Western blotting}

Human normal tissues were frozen in liquid nitrogen vapors and stored at $-80^{\circ} \mathrm{C}$. Fifteen to $3020 \mu \mathrm{m}$ cryostat sections were lysed in buffer containing $50 \mathrm{mM}$ Tris $\mathrm{pH} 7.4,1 \%$ Triton X-100, $150 \mathrm{mM} \mathrm{NaCl}, 200 \mu \mathrm{M} \mathrm{NaVO}_{4}, 1 \mathrm{mM}$ EDTA, 1 mM DTT, $1 \mathrm{mM} \mathrm{NaF}, 1 \mathrm{x}$ final concentration Complete EDTA-free Protease Inhibitor Cocktail Tablets (Roche, Mannheim, Germany) and processed for westen blotting as described ${ }^{16}$.

\section{Immunohistochemistry}

Four- $\mu \mathrm{m}$ thick formalin fixed-paraffin-embedded sections were placed on polylysinated slides. Antigen retrieval was performed in $10 \mathrm{mM}$ citrate buffer, $\mathrm{pH} 6.0$ heated in microwave at $360 \mathrm{~W}$ for $20 \mathrm{~min}$. All subsequent incubations were performed at room temperature: endogenous peroxidase and non-specific sites were blocked by incubation 
with $3 \% \mathrm{H}_{2} \mathrm{O}_{2}$ and $10 \%$ goat serum in PBS/0.05\% Tween-20 for 15 min. Sections were then incubated with anti-mRG $(8 \mu \mathrm{g} / \mathrm{ml})$, anti-PRMT1 $(12 \mu \mathrm{g} / \mathrm{ml})$ or anti-mRG (8 $\mu \mathrm{g} / \mathrm{ml}$ ), for two hours, washed three times with PBST (PBS/0.2\% Tween-20), and incubated for 40 min with the appropriate secondary antibodies: EnVision+ System- HRP Labelled Polymer Anti-Rabbit (DakoEnVision+ ${ }^{\circledR}$, Peroxidase) After 3 washes with PBST, diaminobenzidine (DAB DakoCytomation Liquid DAB+ Substrate Chromogen System) was used as peroxidase substrate for $10 \mathrm{~min}$. 


\section{RESULTS}

Western blot analysis and immunohistochemistry related to methylarginine proteins were performed by utilizing anti-mRG, anti-RG and anti-PRMT1 antisera.

$m R G$ expression in normal human tissues analyzed by western blotting

Western blot analysis of seven normal tissues showed a wide diversity of immunoreactive methylarginine proteins of molecular masses from 30 to $250 \mathrm{kD}$ detected by anti-mRG (Figure 1, upper panel). Although the pattern of reactive protein bands was generally similar, there were perceptible qualitative and quantitative differences among the different tissues with regard to specific protein bands. The control antibody, anti-RG, raised against the non-methylated form of the peptide used to generate anti-mRG, gave a dramatically different staining with recognition of a predominant $70 \mathrm{kDa}$ protein in most tissues (Figure 1, lower panel).

These results confirmed the previously demonstrated specificity of anti-mRG ${ }^{16}$ and indicate the existence of tissue specific variations in the methylarginine expression pattern. The distinctive differences between the anti-mRG and anti-RG western blot staining were also observed by the immunohistochemistry results presented below.

$m R G$ and PRMT1 immunohistochemical expression in normal tissues

Specific nuclear and cytoplasmic mRG immunoreactivity was detected in epithelial and endocrine cells of various organs (Table 1). 
$m R G$ and PRMT1 in epithelia

$\mathrm{mRG}$ was expressed in all the epithelia of the gastrointestinal tract, and most cells of the genito-urinary system. mRG expression was also found in breast, ducts of parotid and sweat glands, acini and ducts of pancreas, bronchioli and pneumocytes Inconsistent staining was detected in fibroblasts of the connective tissues. PRMT1 expression was generally coincident with that of $\mathrm{mRG}$ in the different epithelia. The exception was PRMT1 signal in liver, which was only cytoplasmic with no nuclear staining and fainter than that of mRG (Figures 2a and 2b).

$m R G$ and PRMT1 in hematopoietic and lymphoid tissues

Bone marrow myeloid precursors expressed mRG at variable levels while erythroid precursors as well as megakaryocytes were negative (not shown). There was robust immunostaining associated with lymphoid germinal centers (Figure 2b). In thymus, thymocytes only stained with anti-mRG antibody and PRMT1 was undetectable while macrophagesstained strongly with both antibodies (Figure 3). Macrophagic elements in spleen and lymphoid follicles of the tonsil and appendix expressed high levels of both mRG and PRMT1. By contrast, lung alveolar macrophages expressed high levels of mRG but lacked PRMT1 expression (Figure 3).

$m R G$ and PRMT1 in endocrine tissues

There was high mRG expression in the whole adrenal gland (Cortex shown in figure 2b), thyroid (Figure 4) and islets of Langerhans (Figure 5) and as well as other 
endocrine tissues. The signal intensity from methylarginine in each of these tissues was highest in nuclei.

$m R G$ and PRMT1 in selected tumors

Looking for possible altered mRG expression associated with neoplasia we stained samples of epithelial (colon, gastric and breast) and endocrine (thyroid and pancreas) tumors. The comparison among various cancer histotypes summarized in Table 2 revealed that most breast cancers show a high level of $\mathrm{mRG}$ and only a minority of cases $(4.6 \%)$ shows a low level of staining; thyroid papillary cancers were always immunopositive; the overall the overall reactivity of colon, gastric and pancreatic neoplasms was about $80 \%$ positive. Various patterns of staining were detected: cytosolic, golgi-like, both nuclear and cytosolic and low/undetectable staining (Figure- 6). These patterns appear different from what has been observed in the corresponding normal tissues indicating an underlying heterogeneity of tumor type based on the site and intensity of methylarginine expression. We next wondered if PRMT1 expression could explain these patterns as we observed a correspondence between $\mathrm{mRG}$ staining and PRMT1 expression in normal tissues. We performed this analysis in pancreatic endocrine tumors (PET) where we found that the staining for $\mathrm{mRG}$ corresponds to the staining with anti-PRMT1 antibody in 9 of 10 cases ( 7 positive and 2 negative cases for both antigens) This result suggested that PRMT1 activity was responsible for the majority of the mRG signal detected. The close association between the mRG and PRMT1 staining patterns implies that reduced protein arginine methylation represent a likely molecular explanation for the differential staining in the patient specimens. 


\section{DISCUSSION}

We reported the application of immunohistochemistry to detect arginine methylated proteins (MeRP) in archival paraffin-embedded tissues, which provides rapid, semiquantitative, subcellular cytological and histological data on the methylarginine status in physiologic and pathologic conditions.

Protein arginine methylation is involved in fundamental cellular functions including gene regulation, DNA repair, intracellular protein targeting and signal transduction ${ }^{1,13}$. The possibility to analyze its variation in healthy and diseased tissues is of great interest and will also help in suggesting the mechanisms by which methylation modifications of proteins exert control of diverse cell functions. The intensity of $\mathrm{mRG}$ expression is indeed quantitatively and qualitatively variable in normal tissues, as demonstrated by western blot data and comparison of immunohistochemical staining across different tissues.

Specificity of antibodies. The antibodies used for $\mathrm{mRG}$ detection and control staining reactions have been validated previously by ELISA, western blot and immunoprecipitation ${ }^{16}$. Application of either reagent to the paraffin embedded specimens of control, normal tissue at the same immunoglobulin concentration yields dramatically different outcomes. Negligible to no staining is typical when using the control antibody. Staining alternate serial sections with anti-PRMT1, which recognizes the principal enzyme responsible for the generation of asymmetric dimethylarginine in eukaryotic cells, provides further independent and complementary assessment of antibody 
specificity. Using this approach we demonstrate, for example, that syncytial trophoblasts are devoid of mRG signal and do not express PRMT1. In contrast, the decidual cells are strongly positive for both antigens. The correlation of staining intensity for methylarginine and PRMT1 was demonstrated for nearly all of the other tissues analyzed and supports the conclusion that the anti-mRG antibody specifically detects asymmetric dimethyl-arginine substrates in the same cellular compartment as PRMT1. Few exceptions to this rule were observed. Namely in thymocytes and alveolar macrophages, there was strong $\mathrm{mRG}$ staining, but no expression of PRMT1. In different nearby cells PRMT1 was, however, present, thus excluding the occurrence of artifacts. In such cases we suspect that enzymes other than PRMT1 catalyze the addition of mRG to cell proteins, suggesting the activation of specific signalling pathways in these cell types. Sensitivity of antibodies. The sensitivity of the $\mathrm{mRG}$ detection illustrated in the data images in this report was quite favorable as suggested by a low tissue background and a resultant high signal to noise in all tissues examined. Further evidence of excellent sensitivity can be inferred by a recent study on the functional domains of the $S$. pombe $\mathrm{Rmt} 3$ arginine methyltransferase. Using anti-mRG to assess the ability of Rmt3 variants to methylate ribosomal protein S2 (Rps2), the authors found a relative quantitative correlation between anti-mRG staining of native Rps 2 methylated by the Rmt 3 variants and in vitro radioactive methylation of Rps 2 by the same series of recombinant Rmt3 variants ${ }^{18}$.

Observations on normal tissues. MeRP detectable with anti-RG antibody were widely but not ubiquitously distributed. For example, high expression was detected in germinal centers while the surrounding lymphocytes are negative. This indicates that $\mathrm{B}$ 
cell differentiation/proliferation was associated with the increase of mRG levels. This situation is reminiscent of the role of arginine methylation in the epigenetic transcription events associated with myeloid cell differentiation ${ }^{19}$. The differences in subcellular distribution, along with likely differences of methylation reactions in different normal tissues, will need to be addressed by future studies in order to understand better the possible physiopathological relevance of these findings. An initial step toward this direction was the comparative analysis among normal and neoplastic cells derived from the same tissues presented here and discussed in the following section.

Observations on neoplasia: The distribution of $\mathrm{mRG}$ expression in carcinoma was of particular interest given recent observations regarding the involvement of PRMTs in genome stability $^{20}$, DNA repair ${ }^{21}$ and oncogenesis ${ }^{22}$. The discovery that mRG of p53 is required for the regulation of its activity ${ }^{3,23}$ further highlights the potential importance of the signaling pathways regulated by this post-translational modification in tumors. The potential use of $\mathrm{mRG}$ immunohistochemistry for the study of alterations in protein arginine methylation in primary tumors was suggested by the differential staining observed between normal and neoplastic tissues. Moreover and at variance with the matched normal tissue, cancer showed heterogeneous mRG staining characteristics, both quantitative and qualitative, including perinuclear golgi-like staining or different nuclearto-cytosol ratio, hyper- or hypo-expression (Figures 4 to 6). Several possible molecular alterations that may occur as a consequence of tumorigenesis could give rise to the heterogeneity of tumor staining. Hypo- or, perhaps, hyper-methylation of constitutive protein substrates may lead to aberrant targeting of the methylprotein ${ }^{24}$. Variant alternatively spliced forms of PRMT $1^{9}$ may also influence the staining characteristics of 
$m R G$ and, lastly, differential effects of putative protein arginine demethylases ${ }^{25}$ may play some role in $\mathrm{mRG}$ staining.

Considered together, our results imply that mRG levels are differentially regulated in different tumor types and might thus play various roles in in neoplastic transformation, according to the pathways specific for individual tumor histotypes. This speculation is supported by the observation that gastrointestinal tract and pancreatic endocrine tumors share a similar level of mRG down-regulation (between 20 to 30\%) at variance with breast (4.6\%) and thyroid papillary cancers $(0 \%)$.

Finally, it is important to recognize the limitations of the method that we describe. Since the immunogen used was a repetitive methylation motif common to the majority of methylarginine proteins, a large number of reactive methylarginine proteins could be expected to react with the antibody. We have not formally determined whether the antibody recognizes only asymmetric dimethylarginine or mono-methylarginine and symmetric dimethylarginine as well. We also could not exclude the remote possibility that the antibody will react with free asymmetric dimethylarginine that is not part of a protein amide bonded backbone. The issues of methyl-type specificity will be addressed by future biochemical studies.

In conclusion, this study demonstrated that anti-methylarginine and anti-PRMT1 antibodies can specifically detect the respective antigens in paraffin embedded tissues and can reveal alteration in the expression/processing of $\mathrm{mRG}$. The procedure can be utilized for the study of archival material and the screening of large collections of normal and diseased tissues and, thus, contribute to a greater understanding of the pathophysiological role of arginine methylation. 


\section{REFERENCES}

1. Lee YH, Stallcup MR. Minireview: protein arginine methylation of nonhistone proteins in transcriptional regulation. Mol Endocrinol 2009;23;425-433.

2. Litt M, Qiu Y, Huang S. Histone arginine methylations: their roles in chromatin dynamics and transcriptional regulation. Biosci Rep 2009;29;131-141.

3. Chen $\mathrm{Y}$, Zhou X, Liu N et al. Arginine methylation of hnRNP K enhances p53 transcriptional activity. FEBS Lett 2008;582;1761-1765.

4. Paik WK, Kim S. Natural occurrence of various methylated amino acid derivatives. . New York: John Wiley \& Sons, 1980;8-25.

5. Najbauer J, Johnson BA, Young AL, Aswad DW. Peptides with sequences similar to glycine, arginine-rich motifs in proteins interacting with RNA are efficiently recognized by methyltransferase(s) modifying arginine in numerous proteins. $J$ Biol Chem 1993;268;10501-10509.

6. Bedford MT. Arginine methylation at a glance. J Cell Sci 2007;120;4243-4246.

7. Fisk JC, Sayegh J, Zurita-Lopez C et al. A type III protein arginine methyltransferase from the protozoan parasite Trypanosoma brucei. J Biol Chem 2009;284;11590-11600.

8. Pahlich S, Zakaryan RP, Gehring H. Protein arginine methylation: Cellular functions and methods of analysis. Biochim Biophys Acta 2006;1764;1890-1903.

9. Goulet I, Gauvin G, Boisvenue S, Cote J. Alternative splicing yields protein arginine methyltransferase 1 isoforms with distinct activity, substrate specificity, and subcellular localization. J Biol Chem 2007;282;33009-33021. 
10. Pawlak MR, Scherer CA, Chen J, Roshon MJ, Ruley HE. Arginine Nmethyltransferase 1 is required for early postimplantation mouse development, but cells deficient in the enzyme are viable. Mol Cell Biol 2000;20;4859-4869.

11. Pawlak MR, Banik-Maiti S, Pietenpol JA, Ruley HE. Protein arginine methyltransferase I: substrate specificity and role in hnRNP assembly. J Cell Biochem $2002 ; 87 ; 394-407$.

12. Tang J, Kao PN, Herschman HR. Protein-arginine methyltransferase I, the predominant protein-arginine methyltransferase in cells, interacts with and is regulated by interleukin enhancer-binding factor 3. J Biol Chem 2000;275;19866-19876.

13. Bedford MT, Clarke SG. Protein arginine methylation in mammals: who, what, and why. Mol Cell 2009;33;1-13.

14. Aletta JM, Hu JC. Protein arginine methylation in health and disease. Biotechnol Annu Rev 2008;14;203-224.

15. Tang J, Gary JD, Clarke S, Herschman HR. PRMT 3, a type I protein arginine Nmethyltransferase that differs from PRMT1 in its oligomerization, subcellular localization, substrate specificity, and regulation. J Biol Chem 1998;273;16935-16945.

16. Duan $\mathrm{P}, \mathrm{Xu} \mathrm{Y}$, Birkaya $\mathrm{B}$ et al. Generation of polyclonal antiserum for the detection of methylarginine proteins. J Immunol Methods 2007;320;132-142.

17. Birkaya B, Aletta JM. NGF promotes copper accumulation required for optimum neurite outgrowth and protein methylation. J Neurobiol 2005;63;49-61.

18. Perreault A, Gascon S, D'Amours A, Aletta JM, Bachand F. A methyltransferaseindependent function for Rmt3 in ribosomal subunit homeostasis. $J$ Biol Chem $2009 ; 284 ; 15026-15037$. 
19. Balint BL, Szanto A, Madi A et al. Arginine methylation provides epigenetic transcription memory for retinoid-induced differentiation in myeloid cells. Mol Cell Biol $2005 ; 25 ; 5648-5663$.

20. Yu MC, Lamming DW, Eskin JA, Sinclair DA, Silver PA. The role of protein arginine methylation in the formation of silent chromatin. Genes Dev 2006;20;32493254.

21. Lake AN, Bedford MT. Protein methylation and DNA repair. Mutat Res 2007;618;91-101.

22. Cheung N, Chan LC, Thompson A, Cleary ML, So CW. Protein argininemethyltransferase-dependent oncogenesis. Nat Cell Biol 2007;9;1208-1215.

23. Jansson M, Durant ST, Cho EC et al. Arginine methylation regulates the p53 response. Nat Cell Biol 2008;10;1431-1439.

24. Nichols RC, Wang XW, Tang $\mathrm{J}$ et al. The RGG domain in hnRNP A2 affects subcellular localization. Exp Cell Res 2000;256;522-532.

25. Chang B, Chen Y, Zhao Y, Bruick RK. JMJD6 is a histone arginine demethylase. Science 2007;318;444-447. 


\section{FIGURE LEGENDS}

Figure 1: Methyl-arginine expression in normal tissues by western blotting. Normal human tissues stained with anti-mRG (upper panel) and control anti-RG (lower panel) antibodies. Ponceau stain corresponding to the region of the blot between $50 \mathrm{kDa}$ and $70 \mathrm{kDa}$ (middle panel) demonstrates comparable protein loads. Molecular weight markers are shown on left. Multiple bands are present in most tissues; note the relatively lower signal present in spleen and the presence of a major band in the 50kDa range in pancreas. Control (anti-RG) antibody binds to a predominant band in the $70 \mathrm{kDa}$ range weaker than Comment [MC1]: Speculation about proteolysis has little to no value in this context. that seen with the anti-mRG antibody; note the absence of the immunoreactive anti-RG bar $\stackrel{P}{\equiv}$ spleen and the smear of weak anti-RG reactive bands between 30 to $70 \mathrm{kDa}$ in pancreas.

Figure 2a and b: Methylarginine and PRMT1 expression in normal tissues. The tissues stained are indicated on the left. Note the correspondence between the cells that stain positive for mRG and PRMT1. Objective: 20x (appendix, salivary gland), 40x all the other tissues.

Figure 3: Methylarginine and PRMT1 expression in macrophages. Spleen stained with anti-mRG antibody (A) and the control anti-RG antibody (B), 40x obj. Macrophages of the white pulp (white arrows in A) are stained by anti-mRG (A); note the presence of some tingible body macrophages of the white pulp (black arrow in B) characterized by brown pigment visible without a specific stain. On the right side are shown the myeloid 
cells present in the indicated tissues (A.M.: alveolar macrophage); the arrow in the lung indicates type 1 pneumocytes serving as internal positive control (63x obj); note the lack of PRMT1 staining in alveolar macrophages in comparison with macrophages in the other tissues where both antigens are expressed.

Figure 4: Methylarginine and PRMT1 expression in normal and neoplastic thyroid. Normal thyroid stained with anti mRG (A) and anti-PRMT1 (C), showing nuclear and cytosolic staining for both antigens. Thyroid papillary carcinoma (white arrow) and adjacent non-neoplastic thyroid (black arrow) stained with anti-mRG antibody show a predominant nuclear localization of $\mathrm{mRG}$ antigens in the latter, whereas the tumor exhibits mainly a cytosolic staining (B). Control anti-RG staining is shown in D. $20 \mathrm{x}$ obj.

Figure 5: Methylarginine and PRMT1 expression in normal pancreas and in endocrine tumors. Upper panel: normal human pancreas stained with anti-RG (A) and anti-mRG antibody (B and C). The white arrow indicates a ductule in B and a Langerhans's islet in C. Anti-PRMT1 staining is shown in the inset of C (40x obj.). Lower panel, three different pancreatic endocrine tumors showing a predominant cytosolic staining (D), mixed cytosolic and nuclear staining (E), or no staining (F). 20x obj (63x obj in the insets).

Figure 6: Distinctive patterns and levels of methylarginine protein are detected in colon, gastric and breast cancers. Tumor samples stained with anti-mRG antibody. Example of a colon cancer showing cytoplasmic mRG expression (upper panel) and of a 
colon cancer with perinuclear/Golgi-like signal (lower panel). Examples of gastric and breast cancers with high $\mathrm{mRG}$ cytoplasmic expression are shown in the upper panel, and cases with a faint signal in the lower panels. The inset (63x objective) shown in the lower right image (breast cancer) displays a mitosis where mRG signal is clearly higher than that of the surrounding cells. (20x obj.) 


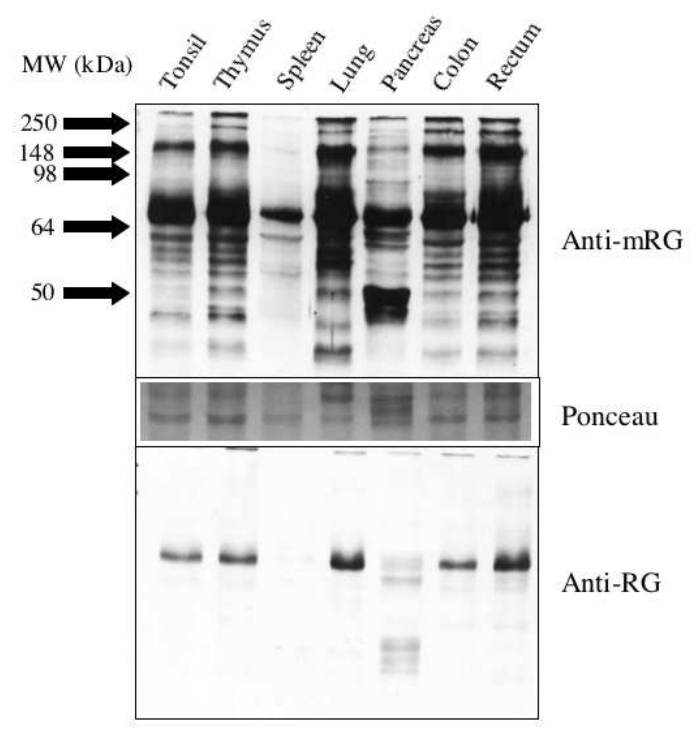




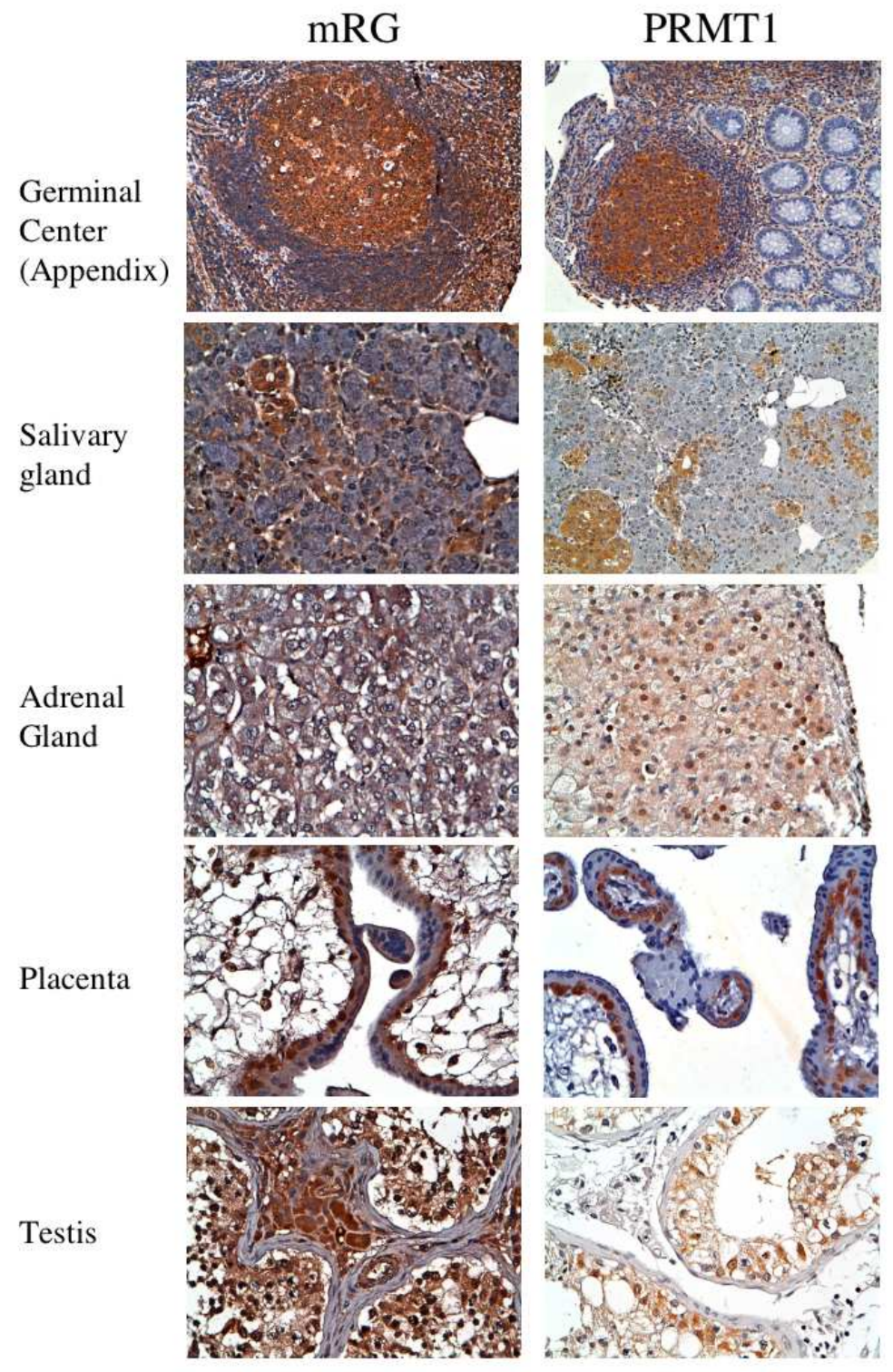




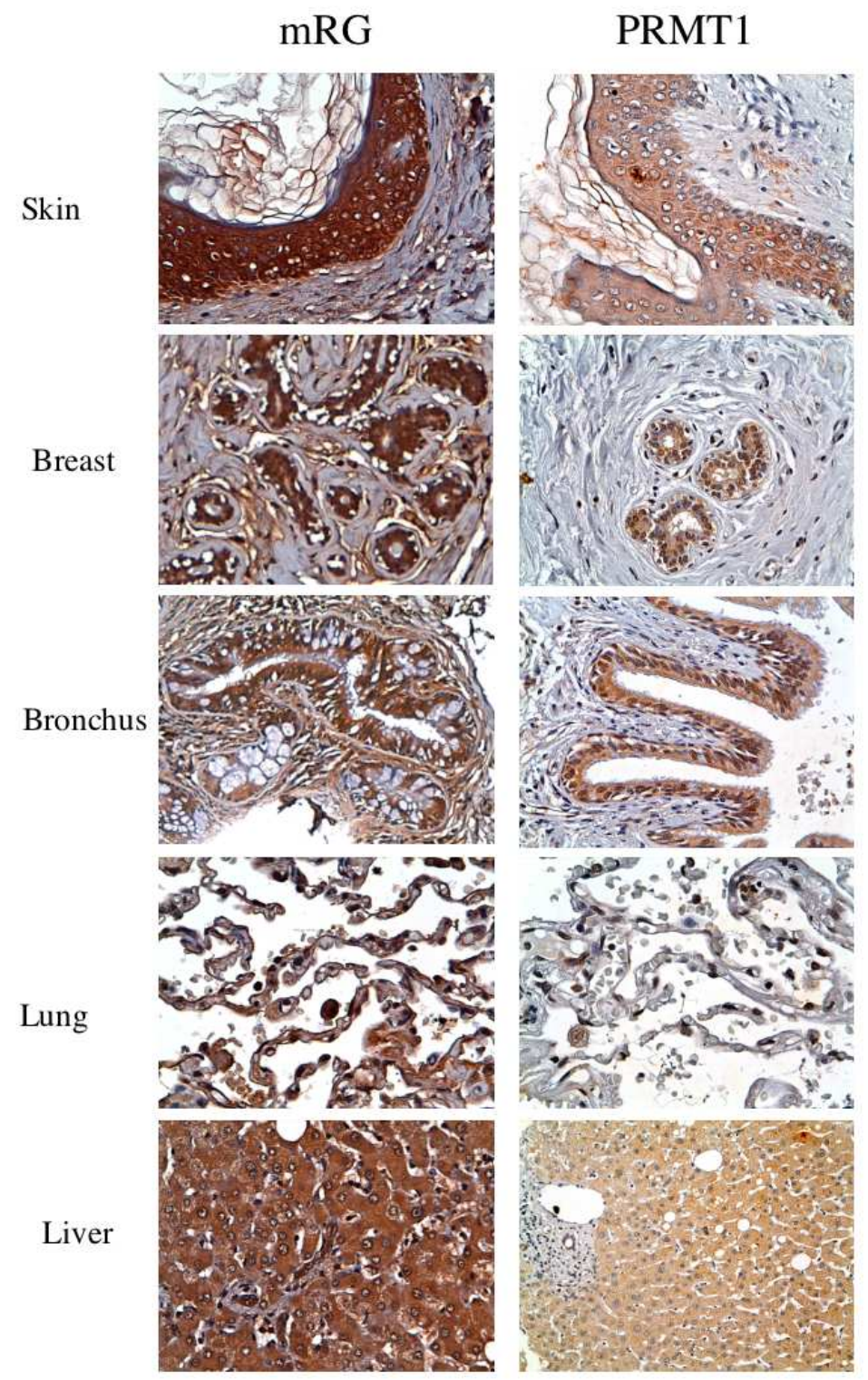


A

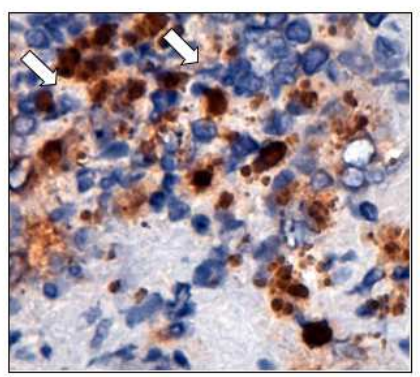

B

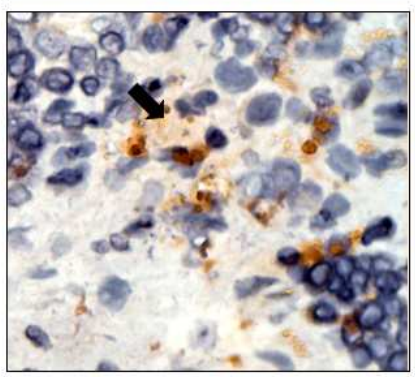

mRG
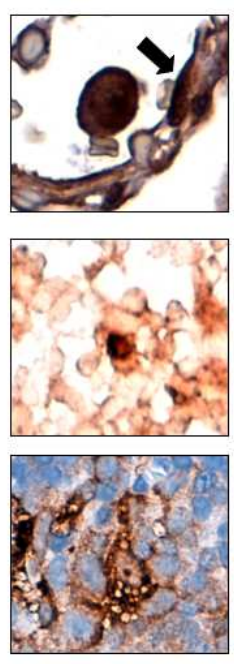

PRMT1
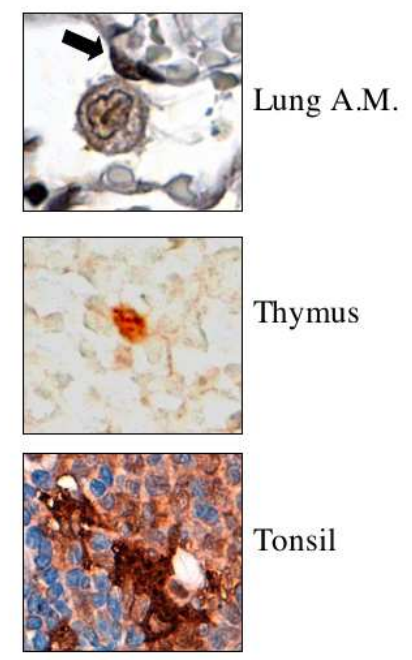

Tonsil 


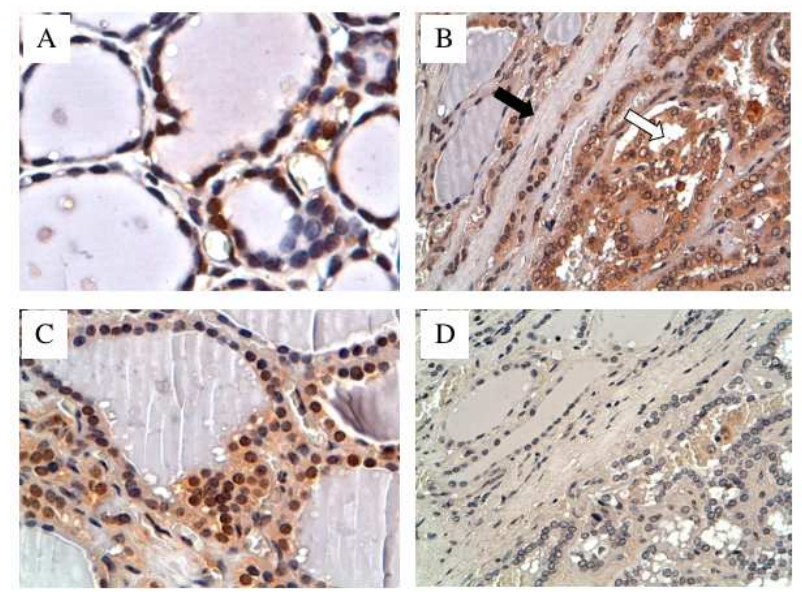



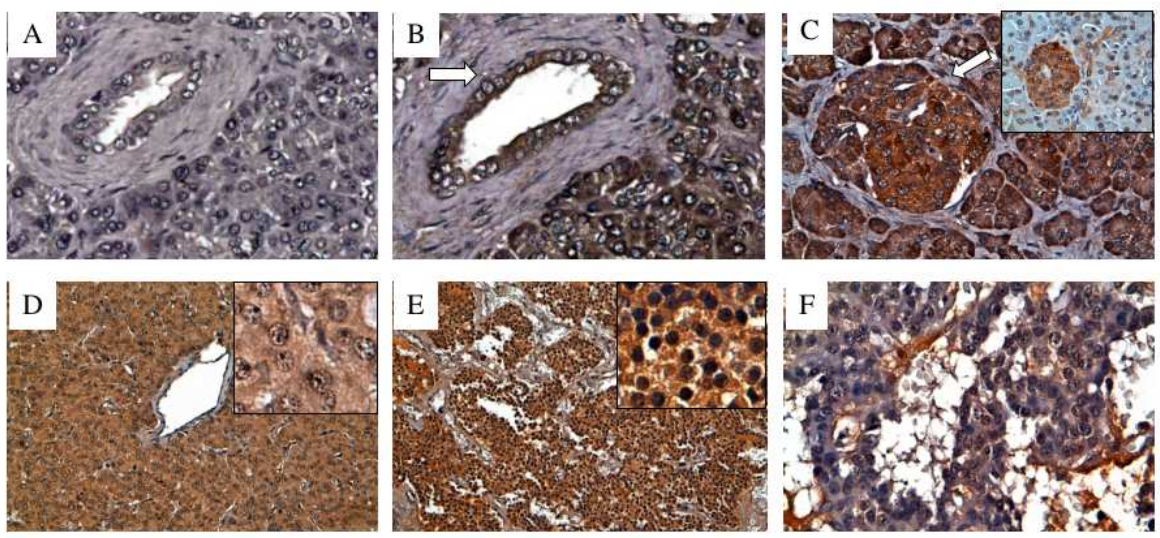

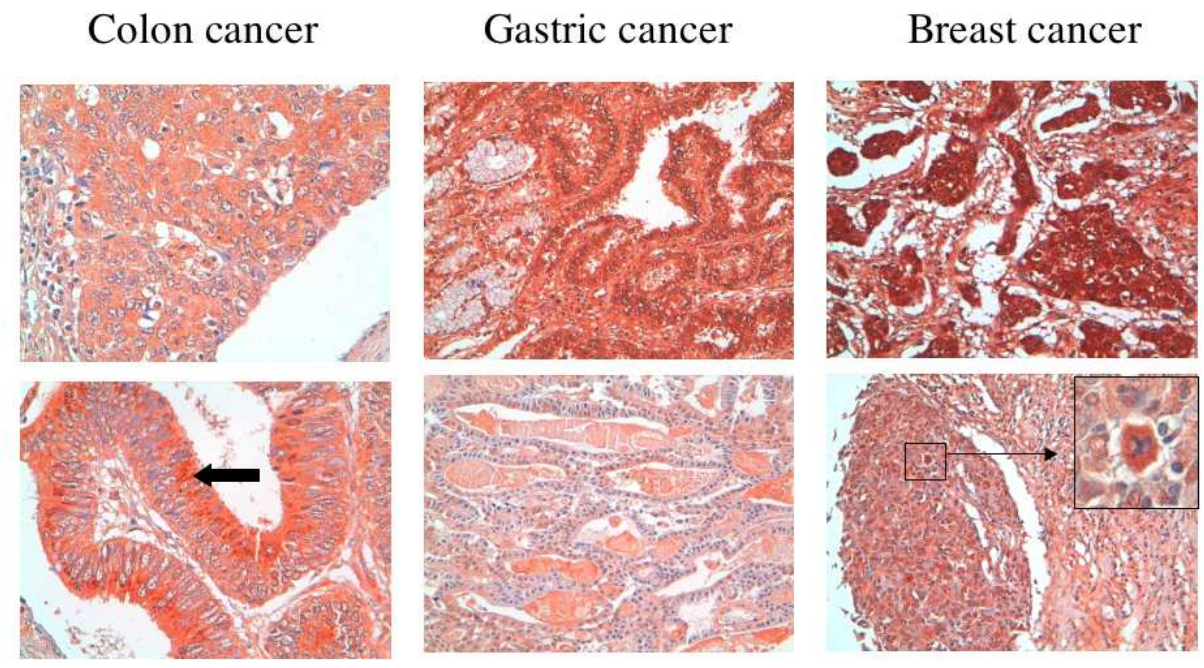
Table 1: Immunohistochemical expression of $\mathrm{mRG}$ and PRMT1 in various tissues and cell types

\begin{tabular}{|c|c|c|c|}
\hline Tissue & Cell type & mRG & PRMT1 \\
\hline Skin & $\begin{array}{l}\text { Squamous epithelium } \\
\text { Sweat glands }\end{array}$ & $\begin{array}{c}+ \\
\text { nd }\end{array}$ & $\begin{array}{c}+ \\
\text { nd }\end{array}$ \\
\hline \multirow[t]{2}{*}{ Parotid } & Duct epithelia & + & + \\
\hline & Acini & - & - \\
\hline \multirow[t]{2}{*}{ Stomach } & Foveolar epithelium & + & + \\
\hline & Gastric glands & + & + \\
\hline \multirow[t]{2}{*}{ Duodenum } & Surface epithelium & + & + \\
\hline & Brunner glands & + & + \\
\hline Small bowel & Surface epithelium & + & + \\
\hline Appendix & Epithelium & - & - \\
\hline Large bowel & Surface epithelium & + & + \\
\hline \multirow[t]{2}{*}{ Liver } & Ductules & + & $+/-$ \\
\hline & Hepatocytes & + & $+/-$ \\
\hline \multirow[t]{2}{*}{ Gall bladder } & Epithelium & + & + \\
\hline & Acini & + & + \\
\hline \multirow[t]{3}{*}{ Pancreas } & Ducts & + & + \\
\hline & Ductules & + & + \\
\hline & Islets of Langerhans & + & + \\
\hline \multirow[t]{3}{*}{ Thyroid } & Thyrocytes & + & + \\
\hline & Parafollicular cells & + & + \\
\hline & Colloid & - & - \\
\hline Parathyroid & Cells & + & + \\
\hline \multirow[t]{2}{*}{ Adrenal } & Cortex & ++ & $+^{*}$ \\
\hline & Medulla & $+/-$ & $+/-$ \\
\hline \multirow[t]{3}{*}{ Bronchus } & Epithelium & + & + \\
\hline & Mucinous glands & - & nd \\
\hline & Serous glands & + & nd \\
\hline \multirow[t]{3}{*}{ Lung } & Pneumocytes type I & + & + \\
\hline & Pneumocytes type II & + & + \\
\hline & Alvolar macrophages & + & - \\
\hline \multirow[t]{2}{*}{ Kidney } & Tubules + & + & + \\
\hline & Glomeruli - & - & - \\
\hline \multirow[t]{2}{*}{ Ureter } & Epithelium & + & $+* *$ \\
\hline & Smooth muscle & $+/-$ & $+/-$ \\
\hline \multirow[t]{2}{*}{ Testis } & Germ cells & + & + \\
\hline & Leydig & ++ & - \\
\hline \multirow[t]{2}{*}{ Prostate } & Epithelial cells & + & nd \\
\hline & Stromal cells & $+/-$ & nd \\
\hline \multirow[t]{2}{*}{ Spermatic ducts } & Epithelium & + & + \\
\hline & smooth muscle & - & - \\
\hline Ovary & Stroma & + & nd \\
\hline Fallopian tube & Serous epithelium & + & nd \\
\hline
\end{tabular}




\begin{tabular}{llcc} 
Uterus & Epithelium & + & + \\
\multirow{3}{*}{ Placenta } & Stroma & $+/-$ & +- \\
& Cytotrophoblast & + & + \\
\multirow{3}{*}{ Breast } & Syncytiotrophoblast & - & - \\
& Endothelium & + & + \\
& Duct epithelia & + & + \\
Bone marrow & Lobular epithelia & + & + \\
& Endometrium & + & + \\
& Megakaryocytes & - & $\mathrm{nd}$ \\
Thymus & Erythroid cells & + & $\mathrm{nd}$ \\
& Macrophages /DC & - & $\mathrm{nd}$ \\
Lymphoid follicle & Lymphoid cells & + & $\mathrm{nd}$ \\
& Epithelial cells & + & $\mathrm{nd}$ \\
& Germinal Center & + & + \\
& Mantle & + & - \\
& Mantle Zone & - & + \\
& FDC & + & + \\
\hline
\end{tabular}

Legend: +, positive; ++, strong positive; +/-, faint positivity; nd, not done;

${ }^{*}$, only nuclei; ${ }^{* *}$, only cytoplasm, FDC: follicular dendritic cells 
Table 2: Expression of $\mathrm{mRG}$ in various neoplasms

\begin{tabular}{lcccc}
\hline Cancer type & Cases & positive & negative & \% negative \\
\hline Thyroid papillary & 8 & 8 & 0 & 0 \\
Breast & 64 & 60 & 4 & 4.6 \\
Colon & 19 & 15 & 4 & 22 \\
Gastric & 32 & 25 & 7 & 21 \\
Pancreatic ductal & 25 & 17 & 8 & 32 \\
Pancreatic endocrine & 10 & 8 & 2 & 20 \\
\hline
\end{tabular}

